\title{
Removal of Acid Yellow 17 from Textile Wastewater by Adsorption and Heterogeneous Persulfate Oxidation
}

\author{
E. Adar $^{1}$ (1)
}

Received: 13 July 2020 / Revised: 27 September 2020 / Accepted: 10 October 2020 / Published online: 26 October 2020

(C) Islamic Azad University (IAU) 2020

\begin{abstract}
Azo dyes commonly used in various industries have a stable and toxic structure. Wastewater containing AY17 dye as a model contaminant was investigated in terms of color and COD removal by both adsorption and persulfate oxidation activated with the PAC. In this study, the effects of temperature $\left(25-50^{\circ} \mathrm{C}\right), \mathrm{pH}(3-10)$, persulfate concentration $(1000-4000 \mathrm{mg} / \mathrm{L})$, adsorbent dosage $(0.1-0.5 \mathrm{~g})$, reaction time (5-60 min), dye concentration (300-1000 $\mathrm{mg} / \mathrm{L}$ ) and $\mathrm{NaCI}$ concentration (0-1000 mg/L) on both color and COD removals from wastewater containing AY17 dye were examined. As a result of the study, it was seen that the dosage of adsorbent, $\mathrm{pH}$ and reaction time are important parameters in both systems. The use of the PAC as an adsorbent caused to shortening of the reaction time in the HPS system. It also showed that acidic and neutral $\mathrm{pH}$ values are more suitable for the removal of AY17 with both systems. Color and COD removal were determined as 100-88.4\% and 100-96.6\%, respectively, at optimum values obtained for the adsorption and HPS system. An experimental design was applied for various operating parameters in order to analyze experimental data. Models have been proposed for both color removal and COD removal estimates for both systems.
\end{abstract}

Keywords Heterogeneous persulfate oxidation $\cdot$ Adsorption $\cdot$ Powder activate carbon $\cdot$ Temperature $\cdot$ Salt $\cdot \mathrm{pH}$

\section{Introduction}

The continuous and rapid development of the industry with the population growth in the world leads to many problems, especially environmental pollution. One of the specific contaminants that cause environmental pollution today is synthetic dyes. Dyestuffs are commonly used in various industries (detergent, soap, silk, etc.), especially in the textile industry, and even their low use generates colored wastewater (Imecik et al. 2014). Wastewater from the textile and dye production industries is among the wastewater group that is difficult to treat. The reason for this is that the dyes generally have a synthetic and complex aromatic molecular structure and these structures make the dyes more stable and more resistant to biodegradation. More than one hundred thousand

Editorial responsibility: Maryam Shabani.

E. Adar

aelanur@artvin.edu.tr

1 Department of Environmental Engineering, Faculty of Engineering, Artvin Coruh University, Seyitler Campus, 08100 Artvin, Turkey synthetic dye types are used commercially worldwide, and it is estimated that approximately 700,000 tons are produced annually. Azo dyes, which are characterized by nitrogennitrogen double bonds $(\mathrm{N}=\mathrm{N})$, constitute the largest and most important commercial dye class that constitutes 50\% of all commercial dyes (Yang et al. 2011). It is reported that approximately $10-15 \%$ of these dyes are discharged with industrial wastewater. Even in low concentrations, they cause undesired aesthetic problems when discharged to the receiving environment (Deniz and Sengul 2015). Color reduces the luminous transmittance in the receiving environment, negatively affects photosynthetic activity and reduces the dissolved oxygen concentration in the environment. Acid yellow 17 (AY17), an azo dye, is a bisulfonated dichloro anionic. Its water solubility is $70 \mathrm{~g} / \mathrm{L}$ (Teli and Nadathur 2018). It has a wide range of usage areas and is mainly used in the food, textile, paper, personal care and cleaning materials industries (Jedynak et al. 2019).

Traditional applications used in color removal from industrial wastewater may be listed as ion change, adsorption, membrane technologies, filtration, precipitation, coagulation, oxidation (Ziba et al. 2016). Among these methods, adsorption is one of the most effective methods of advanced 
wastewater treatment used to reduce dangerous inorganic/ organic contaminants contained in wastewater due to its high efficiency, simplicity of design, ease of use and suitability for the removal of various dyes (Koklu and Ozer 2018). With adsorption, pollutants are attracted at the molecular level, and soluble and/or gaseous chemicals are bound to the adsorbent surface (Khan et al., 2020a). Adsorption process has attracted attention in recent years due to the efficiency in removing contaminants (for example, endocrine disruptors) (Khan et al. 2020a) that are very stable for conventional methods. The adsorption process is an economical method and provides high-quality product formation. The adsorption process is under the influence of many physicochemical factors such as dye/sorbent interaction, surface area of the adsorbent, particle size, temperature, $\mathrm{pH}$ and contact time. The most commonly used adsorbent in color removal with adsorption is active carbon. Activate carbon, which is coalbased-carbon, is effective due to its large pore volume (Khan et al. 2020a). However, activate carbon is an expensive material and regeneration of spent powder activate carbon (PAC) is difficult (Khan et al. 2020a). It is known that one of the most important factors determining the effectiveness of adsorption process is the adsorbent used (Ertugay 2018). Moreover, adsorption is a method in which degradation and mineralization do not occur completely (Yang et al. 2011). Hybrid systems can be used to minimize or eliminate disadvantages such as lack of mineralization in the adsorption system or the formation of by-products in another system. For example, good efficiency has been obtained by using PAC and ultraviolet rays together in the treatment of pharmaceutical wastewater (Khan et al. 2020b). Sharifi et al. (2019) investigated chromium removal with extractantimpregnated resins using the properties of solvent extraction and ion exchange systems. It was stated by Sharifi et al. (2019) that using the two methods together has a positive effect on the removal of pollutants in the aquatic environment. One of the methods in which degradation and mineralization occur is advanced oxidation processes (AOPs). Persulfate (PS) oxidation process is an AOP used for the removal of organic contaminants. Persulfate having $\mathrm{O}-\mathrm{O}$ bond has $140 \mathrm{~kJ} / \mathrm{mol}$ energy and may independently oxidize organic matter. Persulfate may be activated by temperature, UV/light or transition metals. Many researchers generally have used temperature (Gozmen et al. 2013; Kordkandi and Forouzesh 2014) and/or cheap and non-toxic iron (Wu et al. 2012; Li et al. 2016; Liu et al. 2018; Weng and Tao 2018) to degrade organic contaminants in the PS process. Sulfate radical $\left(\mathrm{SO}_{4}{ }^{--}\right)$which of $2.5-3.1 \mathrm{~V}$ oxidation-reduction potential may be produced by activating persulfate. Activate carbon (AC) is commonly used as an adsorbent in the purification of gases and liquids. Besides being a good adsorbent, it is a catalyst carrier and a catalyst. AC is also involved in advanced oxidation studies (especially with oxidants such as $\mathrm{H}_{2} \mathrm{O}_{2}, \mathrm{O}_{3}$ ) as a catalyst. AC acts as the catalyst of the electron transfer medium, similar to the iron (II) ion in Fenton reactive. It can be said that PS enables this because it is similar to $\mathrm{H}_{2} \mathrm{O}_{2}$ in structure. The predicted reactions (1-2) between PS and AC are as follows (Yang et al. 2011):

$$
\begin{gathered}
\text { ACsurface }-\mathrm{OOH}+\mathrm{S}_{2} \mathrm{O}_{8}^{2-} \rightarrow \mathrm{SO}_{4}^{-} \\
+ \text {ACsurface }-\mathrm{OO}^{\bullet}+\mathrm{HSO}_{4}^{-}
\end{gathered}
$$

$$
\begin{gathered}
\text { ACsurface }-\mathrm{OOH}+\mathrm{S}_{2} \mathrm{O}_{8}^{2-} \rightarrow \mathrm{SO}_{4}^{-\bullet} \\
+ \text { ACsurface }-\mathrm{O}^{\bullet}+\mathrm{HSO}_{4}^{-}
\end{gathered}
$$

Few researchers have used activate carbon to activate PS. Generally, granular activate carbon (GAC) has been preferred (Yang et al. 2011; Li et al. 2017). Yang et al. (2011) performed the degradation of acid orange 7 by activating persulfate with GAC at $25^{\circ} \mathrm{C}$. Li et al. (2017) studied the degradation of acid orange 7 by the electrochemistry combined with GAC catalysis of peroxymonosulfate (PMS) at $25{ }^{\circ} \mathrm{C}$. The mechanism of AC/PS is not completely clear due to the fact that little work has been done on this subject. PAC is more active than GAC and is even added to an industrial sludge system to remove toxic compounds (Khan et al. 2020a). It was aimed to fulfill two purposes by using PAC for PS activation. With the use of PAC in the heterogeneous persulfate (HPS) oxidation system, it was aimed to create $\mathrm{SO}_{4}{ }^{-\bullet}$ by activating PS, and to benefit from the adsorbent property of PAC. Degradation/mineralization of acid yellow 17 as a model contaminant with PAC catalyzed PS oxidation (a hybrid system) was investigated. The objectives of this study are given as follows:

1. To determine whether there is a synergic effect in PAC/ PS combination system,

2. To observe whether PS may be catalyzed by PAC,

3. To investigate which reactive species are involved in oxidation,

4. To observe the difference between the adsorption process with only PAC and the PAC/PS combined system,

5. To examine the effect of different operating parameters (temperature, adsorbent dosage, dye concentration, $\mathrm{pH}$, salt concentration, reaction time and PS concentration) and to optimize/model with Taguchi method,

6. To examine color and chemical oxygen demand (COD) removals, oxidation-reduction potential (ORP) and change of organic bond group properties. 


\section{Material and Methods}

\section{Chemicals}

Acid yellow 17 is a synthetic organic dye used in the textile industry. The molecular structure of AY17 is $\mathrm{C}_{16} \mathrm{H}_{10} \mathrm{Cl}_{2} \mathrm{~N}_{4} \mathrm{Na}_{2} \mathrm{O}_{7} \mathrm{~S}_{2}$. AY17 (CAS number 6359-98-4) was obtained from Sigma Aldrich. $1 \mathrm{~g} / \mathrm{L}$ stock solution was prepared. Firstly, wavelength by doing spectral scanning and COD value of AY17 dye were determined. The wavelength and COD of AY17 dye are $404 \mathrm{~nm}$ and $585 \mathrm{mg} / \mathrm{L}$, respectively. Moreover, $\mathrm{pH}, \mathrm{ORP}$ and ion number of AY17 were determined as $5.82,79.6 \mathrm{mV}$ and $4.41 * \mathrm{e}^{-2} \mathrm{~mol} / \mathrm{L}$, respectively.

$0.1 \mathrm{~N} \mathrm{NaOH}$ and $0.1 \mathrm{~N} \mathrm{H}_{2} \mathrm{SO}_{4}$ (Carlo Erba, 99\% purity) were used for $\mathrm{pH}$ adjustment, and NaCI (Sigma Aldrich, 99.5\% purity) was used to study the salt effect. The reason for choosing $\mathrm{NaCI}$ for salt effect studies is that it is an electrolyte used in the textile industry to increase the adsorption of dye to fibers (Pervez et al. 2020).

Potassium peroxodisulfate $\left(\mathrm{K}_{2} \mathrm{~S}_{2} \mathrm{O}_{8},>99 \%\right.$ purity, SigmaAldrich) was preferred as persulfate chemical. $\mathrm{K}_{2} \mathrm{~S}_{2} \mathrm{O}_{8}$ is also an effective disinfectant and/or oxidant for Norwalk virus, foot and mouth disease, and coronavirus (Salari et al. 2009). All chemicals used in the study are of laboratory quality and distilled water was used in the preparation of the necessary solutions.

The adsorbent used in the study is powder activate carbon (DARCO, Sigma Aldrich, particle size 100 mesh). The $\mathrm{pH}, \mathrm{ORP}$ and ions number of adsorbent were measured as $10.29,-177.5 \mathrm{mV}$ and $1.03 * \mathrm{e}^{+3}$, respectively.

\section{Methods and Systems}

Spectral screening, COD and color analysis of dye solutions were carried out with Spectroquant Prove 300 Spectrophotometer (Merck). pH, ORP and ion number measurements were measured with Mettler Toledo Seven Compact brand $\mathrm{pH}$ meter. Edmund Buhler Incubator HoodTH15 brand heated mixer was used. COD analysis was performed according to the APHA (2012) 5220-D method. COD analysis was carried out at $420 \mathrm{~nm}$ wavelength for concentrations less than $100 \mathrm{mg} / \mathrm{L}$, and at $600 \mathrm{~nm}$ wavelength for concentrations higher than $100 \mathrm{mg} / \mathrm{L}$. Spectroquant TR 320 brand digestion device (Merck) was used for COD analysis.

Brunauer, Emmett and Teller (BET) analysis were performed to determine the physical properties of PAC such as pore size and surface area. Moreover, Fourier transform infrared spectrometer-attenuated total reflectance (FTIRATR) analysis was performed to determine the change in functional groups in both AY17 dye solution and effluents resulting from optimum conditions. FTIR-ATR analysis was performed with Perkin Elmer Spectrum 100 device in the range of $4000-650 \mathrm{~cm}^{-1}$ and Brunauer, Emmett and Teller (BET) analysis were performed with Micromeritics ASAP 2020 device.

The surface area of PAC was measured as $652.5287 \mathrm{~m}^{2} / \mathrm{g}$, pore volume as $0.5490 \mathrm{~cm}^{3} / \mathrm{g}$, micropore volume as $0.1538 \mathrm{~cm}^{3} / \mathrm{g}$, adsorption and desorption pore volumes in the range of pore at $1.7-300 \mathrm{~nm}(0.17-30 \AA)$ as $0.3280 \mathrm{~g} /$ $\mathrm{cm}^{3}-0.3916 \mathrm{~g} / \mathrm{cm}^{3}$, and the average pore width as $3.3655 \mathrm{~nm}$ $(0.34 \AA)$ with nitrogen adsorption-desorption isotherms BET analysis. For an ideal activate carbon, the pore volume should be $0.2-1 \mathrm{~cm}^{3} / \mathrm{g}$, the surface area should be $400-1000 \mathrm{~m}^{2} / \mathrm{g}$ and the pore size should be less than $0.3 \mathrm{~nm}$. It can be said that the PAC used in this study is an ideal activate carbon.

According to the BET classification, it is determined that the adsorption isotherm of PAC is compatible with Type II isotherm type. Type II represents strong contaminant adsorbent interaction and unlimited monolayer/multilayer adsorption (Teli and Nadathur 2018). Type II adsorption isotherm deviates greatly from the Langmuir adsorption model. The intermediate flat region in the isotherm corresponds to the entire single layer (Fig. 1). Type II is very common in the case of physical adsorption and undoubtedly corresponds to the multilayer formation.

\section{Adsorption and Persulfate Oxidation Processes}

The most effective levels of operating parameters as a result of the literature review were selected. The experiment designs created with Taguchi for adsorption and persulfate oxidation are given in Table 1 . The reason why it is operated at two different temperatures is that the temperature is approximately $50{ }^{\circ} \mathrm{C}$ during the dyeing processes in the textile industry (Eren et al. 2010). For this reason, it was studied both at $25^{\circ} \mathrm{C}$ room temperature and $50{ }^{\circ} \mathrm{C}$. High dye

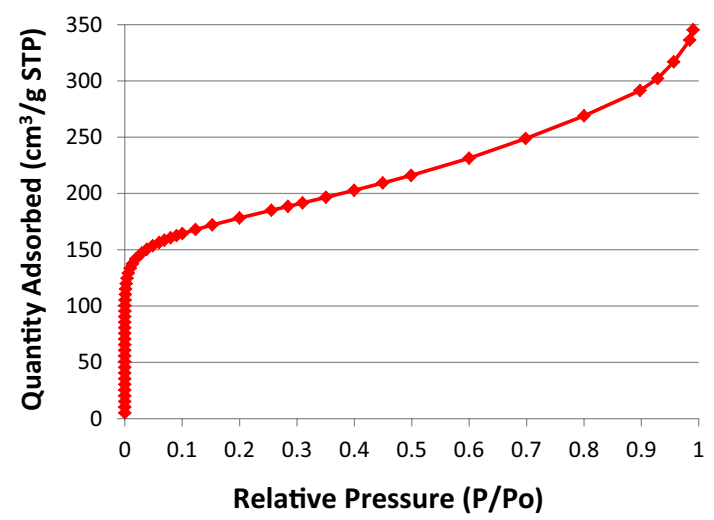

Fig. 1 BET isotherm plot of PAC 
Table 1 Experimental design for adsorption and heterogeneous persulfate systems

\begin{tabular}{|c|c|c|c|c|c|c|c|c|c|}
\hline & $\begin{array}{l}\text { Temperature, } \\
{ }^{\circ} \mathrm{C}\end{array}$ & $\begin{array}{l}\text { Reaction } \\
\text { Time, } \\
\text { min }\end{array}$ & $\mathrm{pH}$ & $\begin{array}{l}\text { Dye Conc., } \\
\mathrm{mg} / \mathrm{L}\end{array}$ & $\begin{array}{l}\text { Salt Conc. for } \\
\text { Ads., } \mathrm{mg} / \mathrm{L}\end{array}$ & $\begin{array}{l}\text { PAC Dosage } \\
\text { for Ads., } g\end{array}$ & $\begin{array}{l}\text { PS Conc., } \\
\mathrm{mg} / \mathrm{L}\end{array}$ & $\begin{array}{l}\text { Salt Conc. for } \\
\text { HPS, } \mathrm{mg} / \mathrm{L}\end{array}$ & $\begin{array}{l}\text { PAC Dosage } \\
\text { for HPS, } \mathrm{g}\end{array}$ \\
\hline 1 & 25 & 5 & 3 & 300 & 0 & 0.1 & 1000 & 0 & 0.1 \\
\hline 2 & 25 & 25 & 7 & 650 & 500 & 0.1 & 2000 & 500 & 0.1 \\
\hline 3 & 25 & 60 & 10 & 1000 & 1000 & 0.1 & 4000 & 1000 & 0.1 \\
\hline 4 & 25 & 5 & 3 & 650 & 500 & 0.3 & 1000 & 1000 & 0.15 \\
\hline 5 & 25 & 25 & 7 & 1000 & 1000 & 0.3 & 2000 & 0 & 0.15 \\
\hline 6 & 25 & 60 & 10 & 300 & 0 & 0.3 & 4000 & 500 & 0.15 \\
\hline 7 & 25 & 5 & 7 & 1000 & 0 & 0.5 & 1000 & 500 & 0.2 \\
\hline 8 & 25 & 25 & 10 & 300 & 500 & 0.5 & 2000 & 1000 & 0.2 \\
\hline 9 & 25 & 60 & 3 & 650 & 1000 & 0.5 & 4000 & 0 & 0.2 \\
\hline 10 & 50 & 5 & 10 & 650 & 1000 & 0.1 & 1000 & 500 & 0.1 \\
\hline 11 & 50 & 25 & 3 & 1000 & 0 & 0.1 & 2000 & 1000 & 0.1 \\
\hline 12 & 50 & 60 & 7 & 300 & 500 & 0.1 & 4000 & 0 & 0.1 \\
\hline 13 & 50 & 5 & 7 & 300 & 1000 & 0.3 & 1000 & 1000 & 0.15 \\
\hline 14 & 50 & 25 & 10 & 650 & 0 & 0.3 & 2000 & 0 & 0.15 \\
\hline 15 & 50 & 60 & 3 & 1000 & 500 & 0.3 & 4000 & 500 & 0.15 \\
\hline 16 & 50 & 5 & 10 & 1000 & 500 & 0.5 & 1000 & 0 & 0.2 \\
\hline 17 & 50 & 25 & 3 & 300 & 1000 & 0.5 & 2000 & 500 & 0.2 \\
\hline 18 & 50 & 60 & 7 & 650 & 0 & 0.5 & 4000 & 1000 & 0.2 \\
\hline
\end{tabular}

concentration and high salt content were taken into account in order to represent the real textile wastewater.

A total of $50 \mathrm{~mL}$ from the dye mixture diluted in appropriate proportion was taken to a flask of $250 \mathrm{~mL}$ for adsorption. The $\mathrm{pH}$ adjustment was made. After adding the appropriate dosage of adsorbent, it was mixed at $120 \mathrm{rpm}$. As soon as the mixing is over, it was filtered through a $0.45 \mu \mathrm{m}$ filter and related experiments were carried out.

The same processes were carried out for persulfate oxidation, and the appropriate dosage of $\mathrm{K}_{2} \mathrm{~S}_{2} \mathrm{O}_{8}$ chemical was added. PAC in the PS process was added less than those added in the adsorption system. The reason for this is to ensure highly active PAC to activate PS, to make the oxidation more dominant compared to adsorption, and to prevent an increase in the cost by using less PAC. The adsorption/ heterogeneous persulfate system used in the study is given in Fig. 2.

\section{Experimental Design}

One of the methods based on the principle of least experimentation to keep the costs to a minimum level is the
Fig. 2 The system used in the study

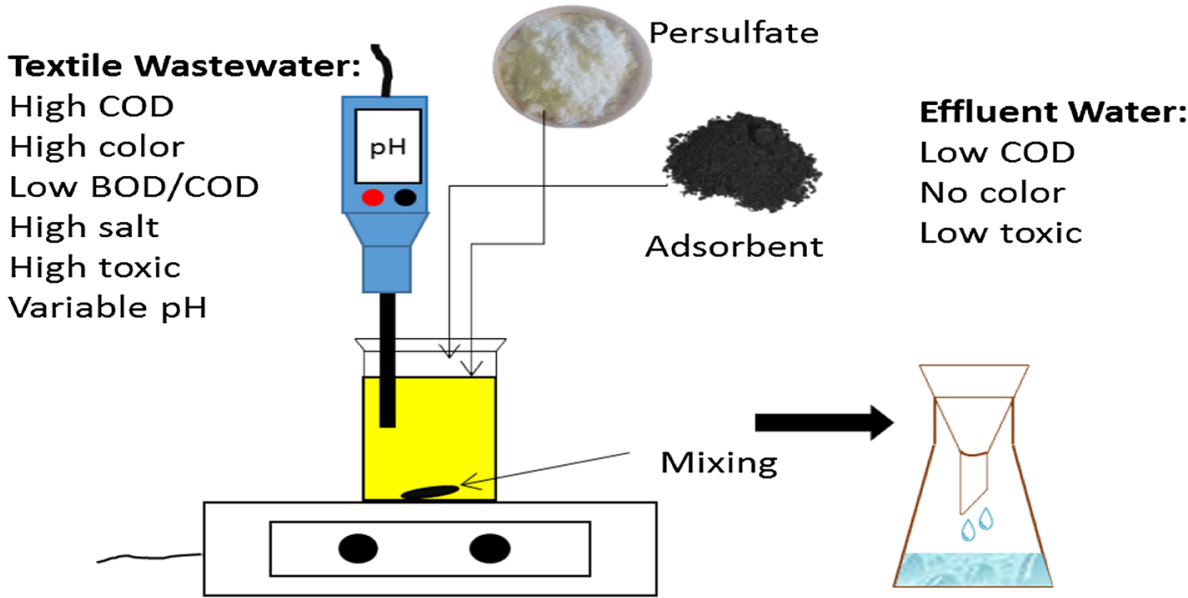

Heterogeneous Persulfate Oxidation Filtration 
"Taguchi method" developed by the Japanese scientist Genichi Taguchi (Erat 2018).

Removal efficiencies (\%) were converted to a signal/noise ratio $(\mathrm{S} / \mathrm{N})$ and evaluated. $\mathrm{S}$ and $\mathrm{N}$ in the $\mathrm{S} / \mathrm{N}$ ratio represent the signal factor and noise factor, respectively. The signal factor refers to the actual value received from the system, and the noise factor refers to factors that cannot participate in the design of the experiment but affect the result of the experiment. Noise sources are the variables that cause the obtained performance characteristics to deviate from the target value. Therefore, the smaller $\mathrm{N}$ value that refers to the noise factors in the $\mathrm{S} / \mathrm{N}$ ratio is, the closer to the desired target value is. There are many the $\mathrm{S} / \mathrm{N}$ ratios in the literature. However, the "best" (1) criterion was used for Nusselt in this study (Serencam and Ucurum 2019). In other words, the aim of this analysis is to maximize $\mathrm{S} / \mathrm{N}$ ratio.

$S / N=-10 * \log \left[\frac{1}{n} \sum_{f=1}^{n} \frac{1}{y_{i}^{2}}\right]$

Here, $y_{i}$ indicates the performance characteristic value (Nusselt number), and $\mathrm{n}$ indicates the number of $Y$ values.

Optimization and statistical analysis in the Taguchi method were carried out by the Minitab 18 program. The Taguchi method is an experimental design using orthogonal arrays. In this study, 6 parameters (temperature is 2 levels, others are 3 levels) were created for adsorption and 7 parameters (temperature is 2 levels, others are 3 levels) were created for heterogeneous persulfate oxidation. L18 (Adsorption: $2^{\wedge} 13^{\wedge} 5$ and HPS: $2^{\wedge} 13^{\wedge} 6$ ) orthogonal array and "the larger is better approach" were used for both systems. Temperature was chosen as $25-50{ }^{\circ} \mathrm{C}, \mathrm{pH}$ as 3-7-10, reaction time as 5-25-60 $\mathrm{min}$, dye concentration as 300-650-1000 mg/L, and salt concentration as 0-500-1000 mg/L for adsorption and HPS process. PS concentration was selected as 1000-2000-4000 mg/L. Adsorbent dosages as $0.1-0.3-0.5 \mathrm{~g}$ in adsorption studies and $0.1-0.15-0.2 \mathrm{~g}$ in HPS oxidation studies were used.

\section{Results and Discussion}

\section{AY17 Removal with Adsorption}

\section{Effects of Operating Parameters on COD Removal}

Acid yellow 17 dye used in different industries was chosen as a model contaminant. Acid yellow 17 dye is a yellow dye and even if it highly mineralizes with advanced oxidation methods such as Fenton, color removal is mostly achieved at low rates. Color is an aesthetically undesirable situation. Moreover, attention should be paid to the complete removal of color in wastewater containing dye since small amounts

\section{Main Effects Plot for SN ratios Data Means}

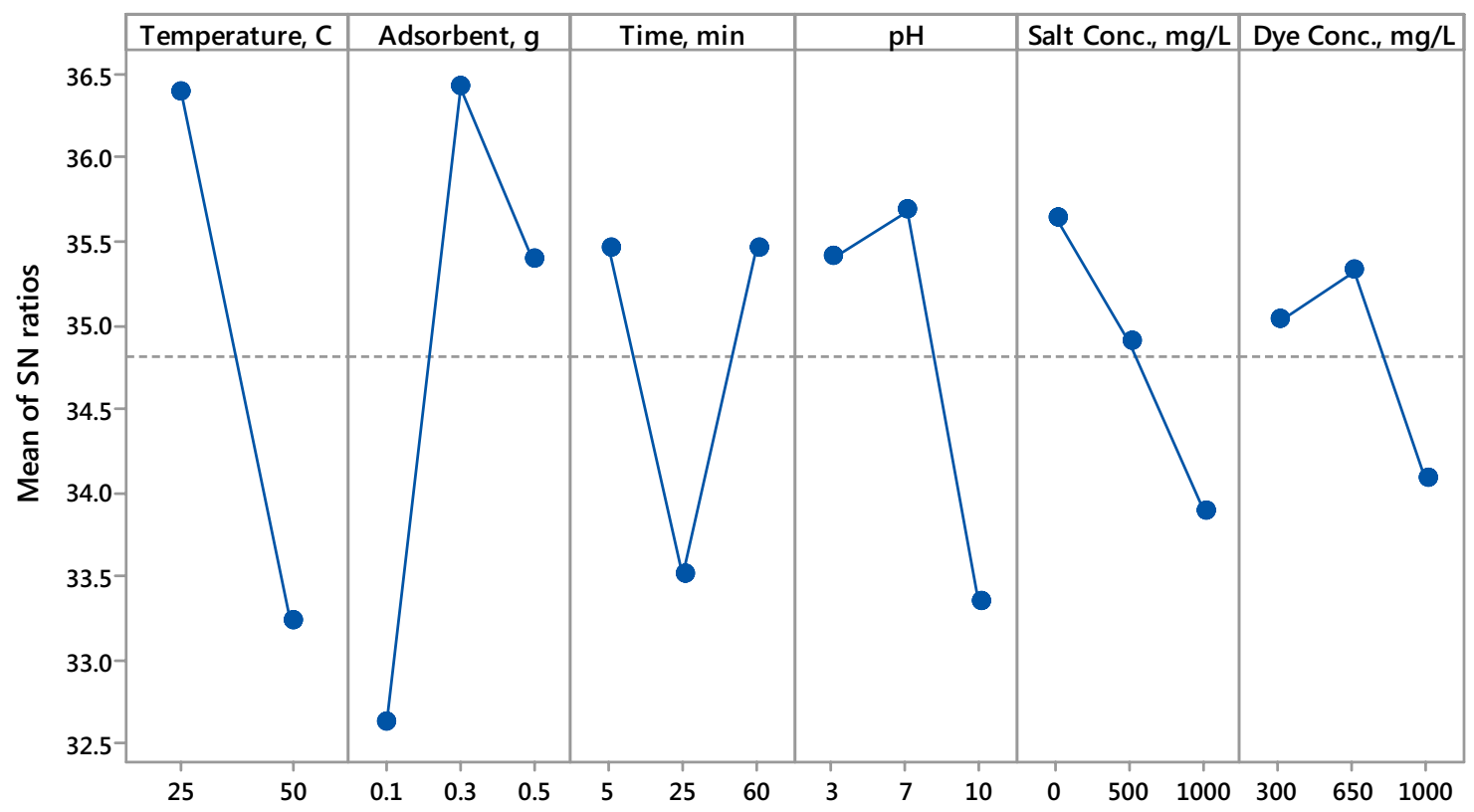

Signal-to-noise: Larger is better

Fig. $3 \mathrm{~S} / \mathrm{N}$ ratios of operating parameters on COD removal for adsorption 
of dyes will cause a colorful appearance. For this reason, the removal of AY17 dye with the adsorption method was investigated at different reaction time, different adsorbent dosage, high temperature, different $\mathrm{pH}$, high salt concentration and high dye concentration to represent real textile wastewater. The results that were obtained for COD removal are given in Fig. 3 as $\mathrm{S} / \mathrm{N}$ ratios. The highest values are optimum values because "the larger is better approach" is used for COD removal efficiency.

COD removal efficiencies were obtained in the range of 33.7-85\%. COD removal efficiencies under the conditions of sample 17 and sample 1 were obtained as $33.7 \%$ and $85 \%$, respectively. The increase in temperature and salt concentration on COD removal efficiency had a negative effect, and other parameters had a nonlinear effect. The highest $\mathrm{S} / \mathrm{N}$ ratios were observed at $25^{\circ} \mathrm{C}, 5 \mathrm{~min}$ (considering cost), $0.3 \mathrm{~g}$ adsorbent, $650 \mathrm{mg} / \mathrm{L}$ dye concentration, $\mathrm{pH} 7$ and $0 \mathrm{mg} / \mathrm{L}$ salt content. Under optimum conditions, $88.4 \%$ COD removal efficiency was obtained.

COD removal efficiency decreased with increasing temperature. The adsorption may be less with an increase in the diffusion rate of dye molecules and Brownian movement due to increasing temperature. Moreover, an increase in the solubility of the dyes may cause low COD removal (Dincer et al. 2019). The temperature may not have been able to create active regions on PAC surface since PAC is already activated at high temperatures.

PAC used is very active, and it was achieved high efficiency even with small amounts. As the dosage of adsorbent increased, COD yield increased to a certain level and then decreased. The highest COD removal was obtained by adding $0.3 \mathrm{~g}$ PAC. The oxidation mechanism needs to be more dominant for COD removal. Particle interaction (aggregation) may be the reason why COD removal does not have a linear increase with the increasing adsorbent dosage. Aggregation may have decreased surface area and increased diffusion path length (Tony et al. 2019).

It is expected that the adsorption efficiency will increase with increasing time. However, such a linear change was not observed in COD removal. Approximately, the same efficiency was obtained in $5 \mathrm{~min}$ and $60 \mathrm{~min}$. Low efficiency in 25 min shows that the adsorbent and contaminant interaction is low. Aggregation may have possibly occurred.

$\mathrm{pH}$, a parameter that controls the magnitude of electrostatic charges given by ionized dye molecules, affects the adsorption mechanism. In other words, it may change the surface charge of the adsorbent and the degree of ionization of functional groups. The highest COD removal was obtained at pH 7. Acidic conditions also provided higher COD removal compared to alkali conditions. The structure of the dye is also an important factor. For example, Salleh et al. (2011) have stated that high removal efficiency at high $\mathrm{pH}$ was obtained in the study of cationic dye removal by adsorption. The dye used in this study is anionic and provided better COD removal efficiency at neutral or weakly acidic $\mathrm{pH}$. It was concluded that the adsorption process is significantly affected by $\mathrm{pH}$. The active regions of the adsorbent may be negatively charged as a result of the degradation by $\mathrm{pH}$ increase. Since the anionic dye is negatively charged, in this case, the effect of the adsorption event (chemical reaction) may be reduced by creating a driving force between the organic molecules and the adsorbent.

COD removal efficiency decreased as salt content increased. The highest $\mathrm{S} / \mathrm{N}$ ratios were obtained under conditions without salt. Salt content, one of the substances that interfere with COD, can be said to interfere in the operating conditions studied. One of the most important reasons for the salt content to affect negatively may be the properties of the dye and adsorbent used. In the study conducted with a different adsorbent and cationic dye, it was observed that the salt content did not negatively affect the COD removal efficiency (unpublished study).

As the dye concentration increased, there was no linear change in COD removal efficiency. The highest removal efficiency was obtained at $650 \mathrm{mg} / \mathrm{L}$ dye concentration. With the increasing dye concentration, it will compete with the dye molecules and formed intermediates to contact/ adsorb the adsorbent surface. This will lead to a decrease in efficiency.

As a result of the regression analysis, the Eq. (4) obtained for COD removal is given below. $R^{2}$ value was determined as 53.35. Considering the coefficients in the equation, the most important parameters for COD removal efficiency are the adsorbent dosage, $\mathrm{pH}$ and temperature, respectively. The least effective parameter is the dye concentration. The reason for the low effect of dye concentration may be that it has already been studied at high concentrations.

$$
\begin{aligned}
\text { COD Removal }(\%) & =102.3-0.842 * \text { Temperature } \\
& +41.7 * \text { Adsorbent } D .-0.007 * R . \text { Time } \\
& -2.29 * \mathrm{pH}-0.0116 * \text { Salt } C . \\
& -0.0047 * \text { Dye } C .\left(R^{2}=53.35\right)
\end{aligned}
$$

\section{Effects of Operating Parameters on Color Removal}

The effect of various parameters that represent the real textile wastewater on color removal efficiency using AY17 dye is examined and $\mathrm{S} / \mathrm{N}$ ratios of these parameters are given in Fig. 4. The highest values are the optimum values since high color removal efficiency is desired.

Color removal efficiency was obtained in the range of 39-100\%. Color removal efficiencies under the conditions of sample 11 and sample 8 were obtained as $39 \%$ and $100 \%$, respectively. It has been observed that the dosage of 


\section{Main Effects Plot for SN ratios Data Means}

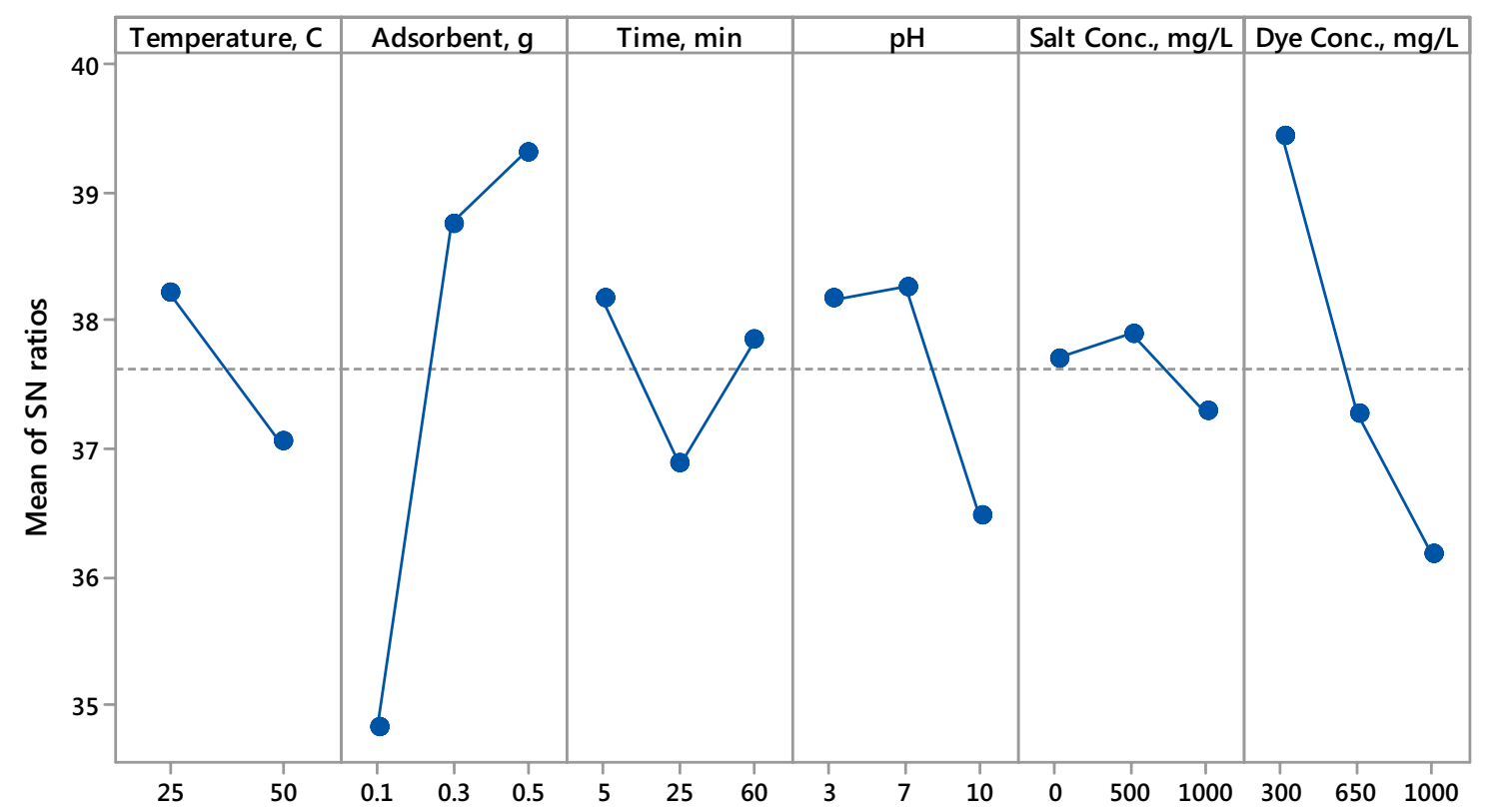

Signal-to-noise: Larger is better

Fig. $4 \mathrm{~S} / \mathrm{N}$ ratios of operating parameters on color removal for adsorption

adsorbent has a positive effect, temperature and dye concentrations have a negative effect, and other parameters have no linear effect on color removal. The highest $\mathrm{S} / \mathrm{N}$ ratios for color removal were obtained at $25{ }^{\circ} \mathrm{C}, 5 \mathrm{~min}, 0.5 \mathrm{~g}$ adsorbent, $300 \mathrm{mg} / \mathrm{L}$ dye concentration, $\mathrm{pH} 7$ and $500 \mathrm{mg} / \mathrm{L}$ salt concentration. Color removal was achieved as $100 \%$ at the highest $\mathrm{S} / \mathrm{N}$ ratios obtained.

The color removal efficiency decreased as the temperature increased. The temperature affects the adsorption capacity and the diffusion rate of the molecules, and changes the time of the adsorption balance (Liu et al. 2018). The decrease in color removal efficiency with increasing temperature indicates that the binding regions on the adsorbent surface do not increase. It shows that the activity of adsorbent is low with temperature. The reason for this may be using an adsorbent commercially prepared and activated at high temperatures. Dincer et al. (2019) have stated that $\mathrm{H}_{2}$ bond between adsorbent and dye molecules may be broken as temperature increases (Dincer et al. 2019).

High color removal efficiency achieved as the dosage of increasing adsorbent increased active sites. In other words, the surface area and the binding area of functional groups increase (Khamparia and Jaspal 2016). As with COD removal efficiency, the highest color removal efficiency was obtained in $5 \mathrm{~min}$. Oxidation and adsorption occurring in a short time may be attributed to the adsorbent being very active.
It was determined that the most suitable $\mathrm{pH}$ value for color removal is 7. It is seen in Fig. 4 that near-neutral $\mathrm{pH}$ values are suitable. Ertugay (2018) explained that the most effective $\mathrm{pH}$ conditions in dye removal are near-neutral and alkali conditions rather than acidic conditions. In the present study, it was observed that near-neutral values are suitable for the removal of AY17 dye. The optimum $\mathrm{pH}$ value in dye removal is highly dependent on $\mathrm{pH}$ values of the adsorbent and the dye. The fact that $\mathrm{pH}$ value of PAC used as an adsorbent is 10.29 , in other words, it is alkali, may have made acidic conditions more favorable for color removal. Because it is stated that electrostatic attraction forces increase for adsorption of dyes under acidic or nearneutral conditions (Dincer et al. 2019). pH of AY17 dye is 5.82 , and it is near-neutral value. The electrostatic driving forces between the adsorbent and the dye molecules may be increased as a result of the increase in the number of the same charged groups on the adsorbent under alkali conditions. Hydroxyl $\left(\mathrm{OH}^{-}\right)$ions may be also prevented the adsorption of dye ions under alkali conditions (Dincer et al. 2019). One reason for low efficiency in alkali conditions may be that basic dyes could not be dissolved completely (Pimol et al. 2008).

Salt content had no linear effect. No negative effects on the color removal were observed as in COD removal. Teli and Nadathur (2018) investigated color removal with two different adsorbents in different salt types and contents 
(without salt, $\mathrm{NaCI}, \mathrm{Na}_{2} \mathrm{SO}_{4}$ and $\mathrm{NaNO}_{3}$ ) using acid yellow 17. The best color removal is achieved in the presence of $\mathrm{NaCI}$ when silica nanofiber is used as adsorbent and the best color removal was achieved without salt addition when modified silica nanofiber was used as adsorbent. The conclusion made from this study is that the salt type also has an effect according to the adsorbent used. PAC used in the present study has been adversely affected by $\mathrm{NaCI}$ salt content, especially in terms of COD removal, and high color and COD removals have not been achieved at high salt concentrations.

As the dye concentration increased, color removal decreased. It is not a surprising result that as the dye concentration increases, the functional groups that need to adhere/ adsorb to the surface will increase. However, there are also inconsistent studies. In these studies, it was stated that the increase in the driving force of the concentration gradient provides this (Gao et al. 2010). Of course, there is the driving force of concentration gradient. However, there may be a low driving force of concentration gradient at high dye concentrations ( $>100 \mathrm{mg} / \mathrm{L}$ ). It can be said that the properties of the adsorbent used are a factor that most affects this situation.

As a result of the regression analysis, the Eq. (5) obtained for COD removal is given below. $R^{2}$ value was determined as 83.91. Considering the coefficients in the equation, the most important parameters for COD removal efficiency were the adsorbent dosage, $\mathrm{pH}$ and temperature, respectively. The least effective parameter was the salt concentration.

ColorRemoval $(\%)=107.6-0.412 *$ Temperature

$$
\begin{aligned}
& +87.6 * \text { Adsorbent } D .-0.017 * R . \text { Time } \\
& -1.1966 * \mathrm{pH}-0.00242 * \text { Salt } C . \\
& -0.03704 * \text { Dye } C .\left(R^{2}=83.91\right)
\end{aligned}
$$

\section{AY17 Removal with Heterogeneous Persulfate Oxidation}

\section{Effects of Operating Parameters on COD Removal}

The effect of various parameters that represent the real textile wastewater using AY17 dye was examined for heterogeneous persulfate oxidation, and $\mathrm{S} / \mathrm{N}$ ratios of these parameters for COD removal are given in Fig. 5.

Considering S/N ratios of the parameters for COD removal, the increase in temperature, PS concentration and $\mathrm{pH}$ had no positive effect. The increase in other parameters had a positive effect on COD removal. The highest $\mathrm{S} / \mathrm{N}$ ratios for COD removal were obtained at $25^{\circ} \mathrm{C}, 0.20 \mathrm{~g}$ PAC, $1000 \mathrm{mg} / \mathrm{L}$ PS, pH 3, $1000 \mathrm{mg} / \mathrm{L}$ dye, 60 min reaction

\section{Main Effects Plot for SN ratios Data Means}

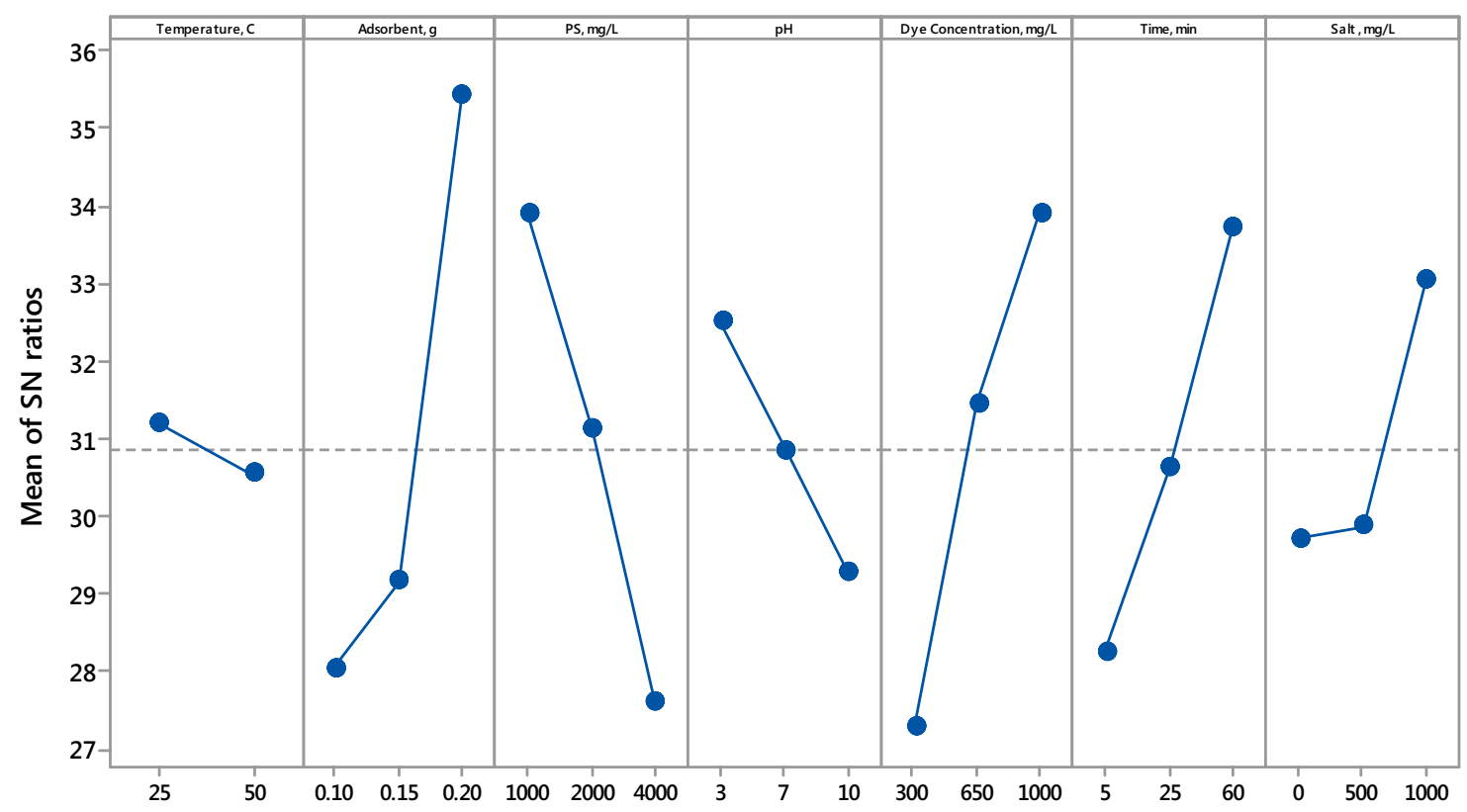

Signal-to-noise: Larger is better

Fig. 5 S/N ratios of operating parameters on COD removal for HPS 
time, $1000 \mathrm{mg} / \mathrm{L} \mathrm{NaCI}$. Under these conditions determined as optimum, 96.6\% COD efficiency was obtained.

COD removal efficiency was negatively affected as the temperature increased. PS reactions usually progress slowly under room conditions. Different agents (high temperature, ultraviolet rays and transition metals) are used to activate $\mathrm{S}_{2} \mathrm{O}_{8}{ }^{2-}$ (Salari et al. 2009). Sulfonamide antibiotics were better removed with increasing temperature when the Materials Institute Lavoisier-101 (Cr) as an adsorbent was used in the study conducted by Peng et al. (2019a). In this study, high efficiency was achieved for both mineralization and adsorption mechanisms at $25^{\circ} \mathrm{C}$. The reason for this may be the use of PAC in the PS system. PAC was an active adsorbent and had a positive effect on both systems (adsorption and heterogeneous PS oxidation).

As the dosage of adsorbent increased, COD removal efficiency increased. Because the wider surface area increases the number of active sites for adsorption and activation (oxidation) mechanisms of PS. This situation was also observed in the study of Yang et al. (2011) about the oxidation of acid orange 7 dye with GAC at $25^{\circ} \mathrm{C}$. It was found that phenol removal was not achieved well with only peroxymonosulfate (PMS), GAC, PMS/GAC and 85\% phenol removal was achieved in $90 \mathrm{~min}$ in PAC/PMS process (Saputra et al. 2013). The result of present study shows that the properties of the adsorbent used in the mineralization of organics have an important effect. The use of adsorbent in the PS oxidation system provides deep treatment of organic pollutants because the continuous adsorption and oxidation take place in the system (Peng et al. 2019a). Having enough oxidants can completely decompose organic contaminants (even intermediate products) in the water. The use of adsorbents in the PS system reduces the use of excess oxidants. Peng et al. (2019a) explained that collecting pollutants with adsorbents and then oxidizing them with PS is an economical way (Peng et al. 2019a). Pollutants are not degraded by the adsorption method. PS oxidation is not as economical as the adsorption method in the removal of low concentration organics. If the adsorbent itself, like PAC, is a catalyst that can rapidly degrade pollutants, contaminants in the adsorption sites can decompose and be released, re-adsorb residual pollutants and quickly re-decompose. In short, the use of adsorbents such as PAC provides a synergistic effect in the PS oxidation system (Peng et al. 2019b).

The highest $\mathrm{S} / \mathrm{N}$ ratio was obtained under conditions in which $1000 \mathrm{mg} / \mathrm{L}$ PS concentration. Increased PS concentration means that there is more sulfate in the environment. The increased sulfate radical reacts with each other and may turn into $\mathrm{S}_{2} \mathrm{O}_{8}{ }^{-2}$ (Reaction 6) (Yang et al. 2010). This may result in less COD removal (oxidation mechanism) at high PS concentrations. The excess sulfate is undesirable due to the salt effect. The excess amount may be determined by appropriate analysis methods (Wang and Wang 2018).
Regardless of the ratio of peroxide to contaminant, PS was reported to provide better efficiency compared to other peroxides (peroxymonosulfate and hydrogen peroxide) (Yang et al. 2010). $\mathrm{SO}_{4}{ }^{--}$is less affected by impurities in water. Increasing PS dosage means increasing the supply of active species (Peng et al. 2019a).

$\mathrm{SO}_{4}^{--}+\mathrm{SO}_{4}^{\cdot-} \rightarrow \mathrm{S}_{2} \mathrm{O}_{8}^{2-}$

A decrease in mineralization with increasing PS was also seen in the study on the activation of PS with $\mathrm{Fe}^{2+}$ (Gozmen et al. 2013). Hori et al. (2005) and Chu et al. (2006) also concluded that the increase in organic degradation slows down when PS over a certain value is used. It was reported that $\mathrm{SO}^{\bullet-}$ produced as a result of activation of PS performs reaction with PS to form $\mathrm{SO}_{4}{ }^{2-}$ (Yang et al. 2011). The composition of the treated water matrix affects degradation (Waclawek et al. 2017). In short, in the literature, it was stated that an increase in PS concentration up to a certain point positively affects efficiency, and after one point, its increase slows or decreases efficiency. The reasons for this are; firstly, it is suitable for the production of reactive species with the increase in PS, which provides the appropriate amount of reactive for the oxidation of contaminants, and it enables easy reaction with the catalyst. Secondly, excessive use of PS decreases the formation of both economic and sulfate radicals (Pervez et al. 2020). In other words, the sulfate radical may react with each other and turn into $\mathrm{S}_{2} \mathrm{O}_{8}{ }^{2-}$, this may lead to a decrease in efficiency.

The higher COD removal efficiency was obtained under acidic conditions ( $\mathrm{pH} 3$ ). This result indicates the need for optimization of $\mathrm{pH}$ in the PS oxidation system (Peng et al. $2019 \mathrm{~b}$ ). If the solution $\mathrm{pH}$ value is $>8.5, \mathrm{SO}^{\bullet-}$ starts to degrade and rapidly turns into $\mathrm{OH}^{\bullet}$. In other words, $\mathrm{OH}^{\bullet}$ will be more dominant at high pH (Yang et al. 2010). For this reason, COD removal is negatively affected by increasing pH. $\mathrm{pH}$ value also changes the effect of anions (carbonate, bicarbonate, chloride and hydrogen phosphate) in the environment. Some anions were reported to be radical scavengers in the $\mathrm{pH}$ range of 8-8.6 (Yang et al. 2010). The most important parameter affecting $\mathrm{pH}$ is considered to be the properties of the adsorbent. Because the $\mathrm{pH}$ of the adsorbent was measured above 10. Acidic or near-neutral values are required for adsorption of contaminant to an alkali adsorbent surface. In the HPS oxidation system, suitable $\mathrm{pH}$ value for both mineralization and color removal was determined as 3 . Under acidic conditions, more adsorption to the adsorbent surface may provide more reaction formation on the surface and there may be an increase in both color and COD removal as a result of the formation of more sulfate radicals (or other radicals). For more accurate results, it is necessary to know both $\mathrm{pH}$ value of the adsorbent at zero charge potential and which radical species predominate with different radical 
scavengers (phenol, methanol etc.). The fact that there is more organic degradation at $\mathrm{pH} 3$ rather than $\mathrm{pH} 7$ as in color removal may be explained by the effect of $\mathrm{pH}$ on the life of the formed radicals. If the hydroxyl radical is more dominant in the environment than the sulfate radical, this idea becomes important. Because the life span of sulfate and hydroxyl radicals is $4 \mathrm{~s}$ and $20 \mathrm{~ns}$, respectively (Yang et al. 2011). The short life span also shows that they cannot diffuse into the bulk phase to react with a contaminant. The $\mathrm{pH}$ provides $\mathrm{H}^{+}$production (Reaction 7) or $\mathrm{OH}^{-}$depletion (Reaction 8) (Lin et al. 2016).

$$
\begin{aligned}
& \mathrm{SO}_{4}^{\bullet-}+\mathrm{H}_{2} \mathrm{O} \rightarrow \mathrm{H}^{+}+\mathrm{SO}_{4}^{2-}+\mathrm{OH}^{\bullet}(\text { All } \mathrm{pH}) \\
& \mathrm{SO}_{4}^{\bullet-}+\mathrm{OH}^{-} \rightarrow \mathrm{SO}_{4}^{2-}+\mathrm{OH}^{\bullet}(\text { Alkali } \mathrm{pH})
\end{aligned}
$$

$\mathrm{HSO}_{4}{ }^{-\bullet}$ will be formed both as a result of the reaction of the hydroxyl radical and sulfate radical, as a result of the degradation of PS or the hydrolysis of PS with water (Reaction 9-10). $\mathrm{HSO}_{4}{ }^{-}$releases $\mathrm{H}^{+}$ions into the environment (Reaction 11) and causes the decreasing of the environment $\mathrm{pH}$ (Lin et al. 2016).

$\mathrm{SO}_{4}^{--}+\mathrm{OH}^{\bullet} \rightarrow \mathrm{HSO}_{4}^{-}+1 / 2 \mathrm{O}_{2}$

$\mathrm{S}_{2} \mathrm{O}_{8}^{2-}+\mathrm{H}_{2} \mathrm{O} \rightarrow 2 \mathrm{HSO}_{4}^{-}+1 / 2 \mathrm{O}_{2}$

$\mathrm{HSO}_{4}^{-} \rightarrow \mathrm{SO}_{4}^{2-}+\mathrm{H}^{+}$

The effect of dye concentration was not studied in most studies. In the studies conducted, concentrations in the range of 5-100 mg/L were preferred (Matzek and Carter 2016; Ahmadi et al. 2016; Li et al. 2017). In this study, high dye concentrations were studied to represent real wastewater. COD removal increased as the dye concentration increased. As far as investigated in the literature, it was stated that increasing dye concentration negatively affects removal efficiency (Salari et al. 2009; Saputra et al. 2013; Pervez et al. 2020). In this study, the color removal efficiency decreases as the dye concentration increases for color removal, while the removal efficiency increases with the increase of dye concentration for COD removal. This result shows that COD removal does not depend on adsorbent dosage as much as color removal. In the adsorption study, the highest COD removal was obtained in less adsorbent and more dye concentration compared to color removal (Fig. 3). These results show that environmental conditions have different effects for color and COD removal and different mechanisms realized for their removal. Moreover, other reactive species formed according to the ambient conditions with increasing dye concentration may have been sufficient for the oxidation of AY17 dye.
As the reaction time increased, in other words, the highest COD removal efficiency was obtained in $60 \mathrm{~min}$. The reason for this may be explained by more radical formation and greater radical-contaminant interaction. Increased reaction time in the oxidation of basic yellow 28 with PS/ $\mathrm{Fe}^{2+}$ also increased the mineralization (Gozmen et al. 2013). Generally, PS oxidation systems operate at longer reaction times. However, the activator used is an important parameter affecting this time. The fact that PAC is very active made this period shorter. Determining the optimum reaction time as $5 \mathrm{~min}$ in the adsorption system is an indicator of the activity of the adsorbent.

Salt content had a linear effect on COD removal. COD yield increased as the salt concentration increased. Chloride content did not inhibit dye mineralization. On the contrary, it can be said that it has an activating effect on the conditions studied. Yuan et al. (2011) investigated the effect of chloride on the removal of acid orange 7 dye by cobalt/peroxymonosulfate AOP. As a result of the study, it has stated that chloride content inhibits mineralization. Peng et al (2019b) investigated the effects of chloride, bicarbonate and natural organic substances on the removal of enrofloxacin by magnetic montmorillonite adsorbent and PS oxidation. Pollutant removal increased with increasing chloride dosage (because HCIO formed), and decreased with increasing content of bicarbonate (because anions are active with increasing $\mathrm{pH}$ ) and natural organic substances (because they are radical scavengers). Chloride ions may also be involved in the persulfate reaction. The sulfate radical may oxidize chloride ions to active species ( $\mathrm{HOCI} / \mathrm{CI}_{2}$ ) or chlorine radicals (Reaction 12-17) (Yuan et al. 2011).

$$
\begin{aligned}
& 2 \mathrm{CI}^{-}+\mathrm{S}_{2} \mathrm{O}_{8}^{2-} \leftrightarrow 2 \mathrm{SO}_{4}^{2-}+\mathrm{CI}^{\bullet} \\
& \mathrm{CI}^{\bullet}+\mathrm{CI}^{-} \leftrightarrow \mathrm{CI}_{2}^{\bullet-} \\
& \mathrm{CI}_{2}^{\bullet-}+\mathrm{CI}_{2}^{\bullet-} \rightarrow \mathrm{CI}_{2}+2 \mathrm{CI}^{-} \\
& \mathrm{CI}_{2}^{\bullet-}+\mathrm{H}_{2} \mathrm{O} \rightarrow \mathrm{CIOH}^{\bullet-}+\mathrm{H}^{+}+\mathrm{CI}^{-} \\
& \mathrm{CIOH}^{\bullet-}+\mathrm{H}^{+} \leftrightarrow \mathrm{CI}^{\bullet} \mathrm{H}_{2} \mathrm{O} \\
& \mathrm{CIOH}^{\bullet-} \leftrightarrow \bullet \mathrm{OH}+\mathrm{CI}^{-}
\end{aligned}
$$

Chloride, dichloride radical and all types of reactive chlorine including free chlorine may bind to the unsaturated bonds of the compounds present during oxidation processes and produce chlorinated hydrocarbons and cause an undesirable increase in the adsorbable organic halogens (AOX) parameter. However, AOX removes by the adsorption mechanism by using activate carbon as an activator. Yuan 
et al. (2011) conducted AOX analysis in their studies and observed that some persistent by-products were formed as a result of the analysis. In the present study, AOX analysis could not be performed. However, the realization of adsorption mechanism in a system especially for wastewater with salt content (wastewater has usually salt content) may reduce the formation of by-products.

Yang et al. (2010) investigated the degradation of acid orange 7 with three common peroxides (persulfate, peroxymonosulfate and hydrogen peroxide) using temperature, UV rays and anions (sulfate, nitrate, carbonate, bicarbonate, chloride and hydrogen phosphate) as activators. PS was observed to be activated above $50{ }^{\circ} \mathrm{C}$. The effect of anions varied depending on the type used. Liang et al. (2006) observed that there was interference as the concentration of salt increased in the degradation of trichloroethylene contaminant when PS is used as an oxidant in the presence of salt $\left(\mathrm{CI}^{-}\right)$. It was stated that $\mathrm{CI}^{-}$interference is dependent on $\mathrm{SO}_{4}{ }^{--}$production. Shortly, chlorine has an effect as an inhibitor or oxidizer depending on the ambient conditions.

As a result of the regression analysis, the Eq. (18) obtained for COD removal is given below. $R^{2}$ value was determined as 92.07. Considering the coefficients in the equation, the most important parameters for COD removal efficiency were the adsorbent dosage, $\mathrm{pH}$ and reaction time, respectively.

$$
\begin{aligned}
\text { CODRemoval }(\%) & =-9.8-0.211 * \text { Temperature } \\
& +326.3 * \text { Adsorbent } D . \\
& -0.00658 * \text { PS } C .-0.722 * \mathrm{pH} \\
& +0.02805 * \text { Dye } C .+0.2746 * R . \text { Time } \\
& +0.00881 * \text { Salt } C .\left(R^{2}=92.07\right)
\end{aligned}
$$

\section{Effects of Operating Parameters on Color Removal}

The effect of various parameters that will represent the real textile wastewater on HPS oxidation of the model organic contaminant AY17 dye was also examined for color removal, and $\mathrm{S} / \mathrm{N}$ ratios of these parameters are given in Fig. 6.

Considering $\mathrm{S} / \mathrm{N}$ ratios of the parameters for color removal, no positive effect was observed as the temperature and dye concentration increased and the color removal efficiency decreased. As the effect of other parameters was increased, it had positive effects on color removal. The highest $\mathrm{S} / \mathrm{N}$ ratios for color removal were obtained at $25{ }^{\circ} \mathrm{C}$, $0.20 \mathrm{~g}$ adsorbent, $4 \mathrm{mg} / \mathrm{L}$ PS, pH 3, $300 \mathrm{mg} / \mathrm{L}$ dye, $60 \mathrm{~min}$ reaction time, $0 \mathrm{mg} / \mathrm{L}$ salt. In this optimum condition determined, color removal efficiency was measured as $100 \%$.

As the temperature increased, the color removal efficiency was negatively affected. Although the temperature is used as an activator for PS oxidation, it was found to have no effect in this study. There are probably two reasons for this.

\section{Main Effects Plot for SN ratios Data Means}

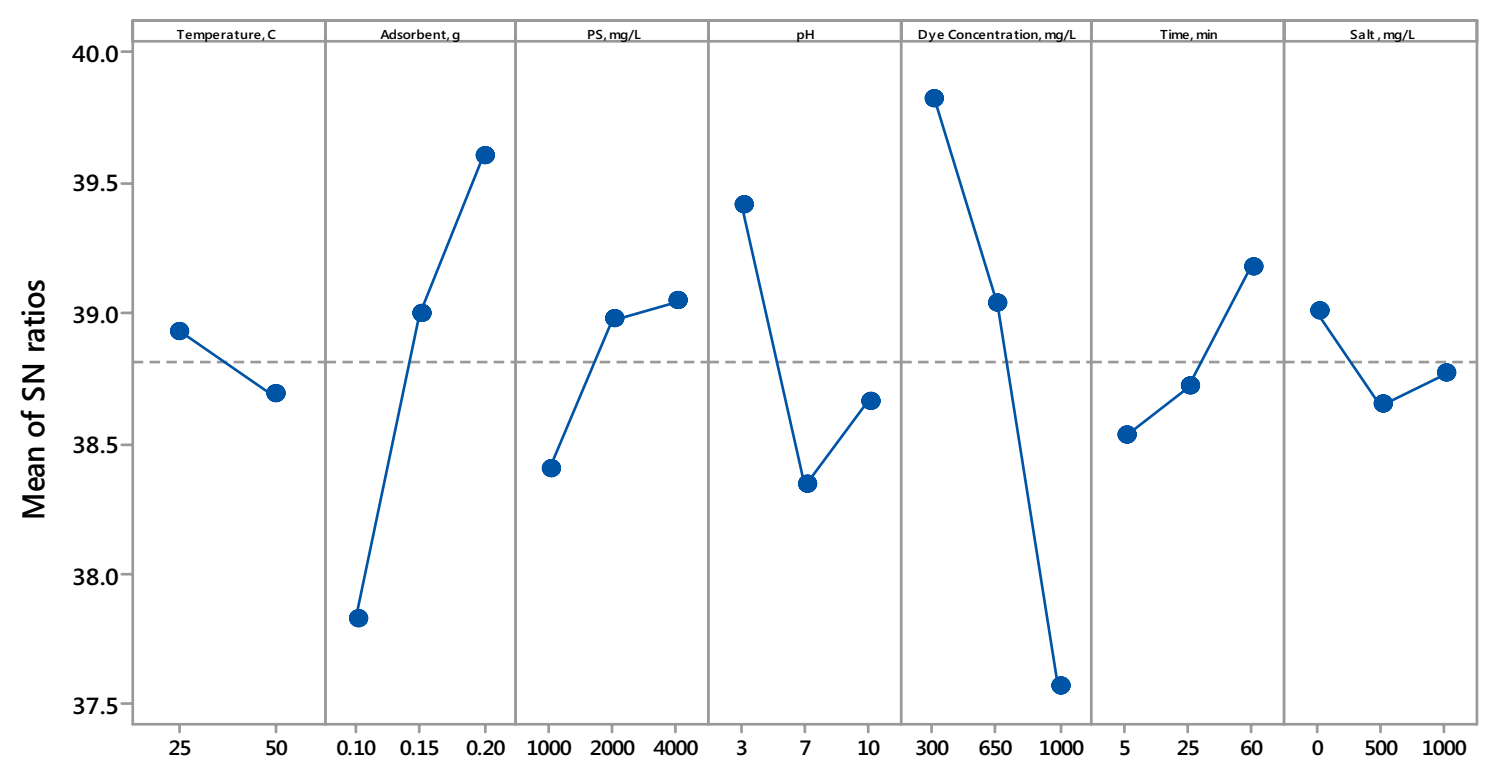

Signal-to-noise: Larger is better

Fig. 6 S/N ratios of operating parameters on color removal for HPS 
The first one is that PAC used is very active, which means that it provides high removal in a short time such as $5 \mathrm{~min}$ in the adsorption study. The second one is that $\mathrm{NaCI}$, which is used to represent real wastewater, may have had a positive effect on activation.

As the dosage of adsorbent increased, the color removal efficiency was positively affected. It is stated that radicals are produced on the adsorbent surface and pores ( $\mathrm{Li}$ et al. 2017). PS is catalyzed with active sites on the surface of activate carbon (AC) and produced sulfate radicals (Reaction 1-2) (Zhang et al. 2013; Li et al. 2017). The removal efficiency was positively affected as the dosage of adsorbent was increased since it has a large surface area on PAC. Since, reactive (mainly sulfate, chlorine, hydroxide radicals, etc.) formed on the surface/pores degrades the dye adsorbed onto the surface and it may spread into the aqueous solution (Li et al. 2017).

The highest $\mathrm{S} / \mathrm{N}$ ratio was obtained at the highest PS concentration $(4000 \mathrm{mg} / \mathrm{L})$ contrary to COD removal. Increased PS concentration means that there is more sulfate in the environment. The increased sulfate radical may react with each other and turn into $\mathrm{S}_{2} \mathrm{O}_{8}{ }^{-2}$ (Reaction 6). This may cause degradation to decrease. In this study, the opposite effect was observed. Increasing PS concentration also enables the formation of different radical species depending on the ambient conditions. The hydroxyl radicals formed may have been sufficient for color removal.

The higher color removal efficiency was achieved under acidic conditions ( $\mathrm{pH} 3$ ). However, the linear change was not observed. It was suggested that $\mathrm{pH}$ value is an important parameter in oxidation systems and it may be studied under acidic conditions for homogeneous systems and at a wide $\mathrm{pH}$ range for heterogeneous systems (Lin et al. 2016).

In this study, it can be said that the high COD and color removals under acidic conditions for the HPS oxidation are mainly due to the properties of the activator used, namely the adsorbent and other operating conditions. Lin et al. (2016) investigated the effect of three different $\mathrm{pHs}$ (3-7-10) on the removal of orange II in the electrocoagulation, $\alpha-\mathrm{FeOOH}$ and peroxydisulfate heterogeneous system. The final efficiency was found to be in the range of 89-92\% at all $\mathrm{pHs}$, and it was stated that $\mathrm{pH}$ had no significant effect. In the GAC/PS system, the highest efficiency was observed at approximately $\mathrm{pH}$ 5. It was stated that near-neutral $\mathrm{pH}$ values are optimum for the degradation of an acidic dye with GAC/PS (Yang et al. 2011).

Color removal decreased as the dye concentration increased. This is a result consistent with studies in the literature. In studies in the literature, it was generally studied at dye concentrations less than $100 \mathrm{mg} / \mathrm{L}$. The reason for the decrease in efficiency with increasing dye concentration is requiring more free radicals for degradation.
Moreover, as the dye concentration increases, the formation of relatively less active free species depending on the ambient conditions ( $\mathrm{pH}$, salt content, etc.) may have led to a decrease in color removal efficiency. In other words, increased dye concentration may produce more free radical scavengers (Ahmadi et al. 2016). Additionally, dye molecules compete with intermediate products to react with reactive species on the adsorbent. In this study, the decrease in efficiency with increasing contaminant concentration also shows that PAC active surfaces reach saturation since PAC is used as an activator. Dye adsorption reduced the catalytic performance by interfering with the electron transfer process (Pervez et al. 2020). Moreover, competition between carbonaceous substances will increase for free radical scavengers and free radicals due to the non-selective reactivity of free radicals. In many studies, the same effect in dye concentration was observed (Salari et al. 2009; Saputra et al. 2013; Frontistis et al. 2015; Pervez et al. 2020).

As the reaction time increased, in other words, the highest COD removal efficiency was obtained in $60 \mathrm{~min}$. It was stated that different radicals may be formed except for the sulfate radical in PS oxidation systems. In the literature, it seems that the life span of sulfate (4 s) and hydroxyl radicals (20 ns) are quite short (Yang et al. 2011). A short life span requires more reaction time to interact with the contaminant even if the sulfate radical is dominant in the environment. Because it may not be possible to interact with all contaminants in $4 \mathrm{~s}$. As the reaction time increases, it will have more contact with the adsorbent, which acts as an activator. Of course, longer reaction time will also result in a decreased or slow increase in efficiency due to intermediate compounds that are difficult to degrade.

Salt content had no linear effect on color removal. As the salt concentration increased, the color removal efficiency decreased. The reason may be that the salt has a negative effect on color removal, and the by-products formed as a result of the reaction of salt and organics caused color formation. In the literature, it was stated that chloride has a dual effect (accelerator or inhibitor) on dye removal. It is stated that high dye removal may be performed at high chlorine concentrations, as well as reducing mineralization and forming more toxic compounds (Salari et al. 2009).

As a result of the regression analysis, the Eq. (19) obtained for COD removal is given below. $R^{2}$ value was determined as 89.05. Considering the coefficients in the equation, the most important parameters for color removal were the adsorbent dosage, $\mathrm{pH}$ and reaction time, respectively. 
ColorRemoval $(\%)=85.35-0.060 *$ Temperature

$$
\begin{aligned}
& +167.7 * \text { Adsorbent } D .+0.00171 * \text { PS } C . \\
& +0.1206 * \text { R.Time } \\
& -0.00195 * \text { Salt } C .\left(R^{2}=89.25\right)
\end{aligned}
$$

When compared to the equations obtained for both COD and color removals, a higher $R^{2}$ value was obtained for COD removal. In the studied conditions, it is seen that the operating parameters that affect both parameters (color and COD) significantly are the same.

\section{Changes of the ORP and FTIR in Effluents for HPS Systems}

In the study on the oxidation of AY17 with heterogeneous persulfate, $\mathrm{pH}, \mathrm{ORP}$ and ion product analysis (Table 2) were performed in the influent and effluent waters, in addition to color and COD analysis. Moreover, FTIR analysis was carried out in the sample in optimum conditions determined in terms of both COD and color removal.

While color removal efficiency was achieved between 68 and 100\%; COD removal was determined in the range of $5.2-72.1 \%$ (Table 2). Despite studying at different $\mathrm{pH}$ values, the $\mathrm{pH}$ of all samples was measured in the range of 2.16-4.36 after the reaction. The change in $\mathrm{pH}$ is an indication of a reaction. Decreasing $\mathrm{pH}$ values during the reaction may indicate that small molecular carboxylic acids are formed (Peng et al. 2019b).
Moreover, the low $\mathrm{pH}$ indicates that the discharge of the effluent to the receiving environment is not suitable for $\mathrm{pH}$ (6-9). The final $\mathrm{pH}$ value may have decreased due to the proton $\left(\mathrm{H}^{+}\right)$release of the acid products formed by reacting with $\mathrm{SO}_{4}{ }^{-\bullet}$ water. This result is compatible with the literature information (Yang et al. 2010; Lin et al. 2016; Li et al. 2017). ORP (oxidation-reduction potential) was measured in the range of $165.2-293.1 \mathrm{mV}$. $\mathrm{pH}$, temperature, etc. of the environment affects ORP. The number (product) of ions was measured in different ranges. It is stated that the higher the $\mathrm{pH}$ value is, the lower the ORP value is (Wu and Wang 2012). High ORP values were measured since $\mathrm{pH}$ values of effluents in the PS oxidation system are low.

As is seen from the Eq. (20) obtained in the regression analysis carried out for the ORP value, the parameter that affects the ORP significantly is the dosage of adsorbent, while the least affecting parameter is the salt content, and $R^{2}$ of the equation is $78.10 \% . R^{2}$ value indicates the degree of relationship of the operating parameters with the ORP. While $\mathrm{pH}$ and dye concentration from operating parameters have ensured low ORP value, the other 5 parameters have ensured an increase in ORP value. In other words, ORP value depends on many parameters and it is a flexible and easy-to-analyze parameter used in treatment systems. Oyekanmi et al. (2019) investigated the removal of Rhodamine $\mathrm{B}$ dye in terms of both color and COD removal using raw orange peel and modified orange peel as adsorbent. As a result of the study, $R^{2}$ values for color and COD removals of raw orange peel and modified orange peel were $73.3-74.55 \%$
Table 2 The changes of the $\mathrm{pH}$, ORP and ion product values in the operating conditions

\begin{tabular}{lllrlll}
\hline Sample No & Initial $\mathrm{pH}$ & Final $\mathrm{pH}$ & Color Removal, $\%$ & $\begin{array}{l}\text { COD } \\
\text { Removal, } \\
\%\end{array}$ & ORP, $\mathrm{mV}$ & Ion Product, mol/L \\
\hline 1 & \multicolumn{7}{c}{$\begin{array}{l}\text { \% } \\
2\end{array}$} & 3 & 3.29 & 88.7 & 26.5 & 226.8 & $1.46 \mathrm{e}^{-4}$ \\
3 & 7 & 3.00 & 78.5 & 23.3 & 243.5 & $7.68 \mathrm{e}^{-5}$ \\
4 & 10 & 2.98 & 72.0 & 41.9 & 244.9 & $7.33 \mathrm{e}^{-5}$ \\
5 & 3 & 2.85 & 93.1 & 57.1 & 252.5 & $5.45 \mathrm{e}^{-5}$ \\
6 & 7 & 2.76 & 79.0 & 55.0 & 257.9 & $4.45 \mathrm{e}^{-5}$ \\
7 & 10 & 3.10 & 100.0 & 5.2 & 238.3 & $9.51 \mathrm{e}^{-5}$ \\
8 & 7 & 2.48 & 100.0 & 72.1 & 274.1 & $2.37 \mathrm{e}^{-5}$ \\
9 & 10 & 3.10 & 93.7 & 67.5 & 238.4 & $9.52 \mathrm{e}^{-5}$ \\
10 & 3 & 2.72 & 95.6 & 52.5 & 260.1 & $4.08 \mathrm{e}^{-5}$ \\
11 & 10 & 4.36 & 59.0 & 38.1 & 165.2 & $1.64 \mathrm{e}^{-3}$ \\
12 & 3 & 2.26 & 100.0 & 26.1 & 287.0 & $1.44 \mathrm{e}^{-5}$ \\
13 & 7 & 2.99 & 75.4 & 10.0 & 244.3 & $7.54 \mathrm{e}^{-5}$ \\
14 & 7 & 3.40 & 68.0 & 51.2 & 220.9 & $1.87 \mathrm{e}^{-4}$ \\
15 & 10 & 2.35 & 100.0 & 15.3 & 281.9 & $1.75 \mathrm{e}^{-5}$ \\
16 & 3 & 2.29 & 99.8 & 43.4 & 285.3 & $1.54 \mathrm{e}^{-5}$ \\
17 & 10 & 2.64 & 99.8 & 69.5 & 264.7 & $3.42 \mathrm{e}^{-5}$ \\
18 & 3 & 2.70 & 85.0 & 62.2 & 261.6 & $3.85 \mathrm{e}^{-5}$ \\
\hline
\end{tabular}




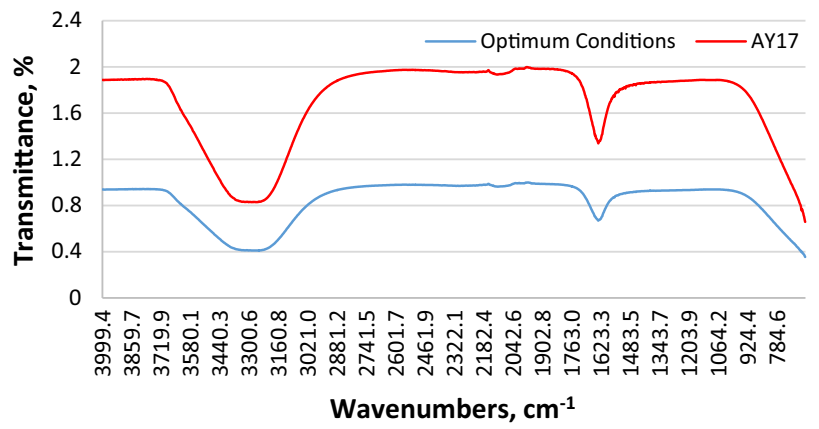

Fig. 7 FTIR results for the HPS optimum conditions (the influent (red) and effluent (blue))

and $96.92-90.06 \%$, respectively. The difference of the correlation coefficient is the indicator that it is affected by the adsorbent property as well as the operating parameters.

$$
\begin{aligned}
\text { ORP } & =212.4+0.300 * \text { Temperature } \\
& +301 * \text { Adsorbent Amount } \\
& +0.00765 * \text { PS } C-3.24 * \mathrm{pH} \\
& -0.0454 * \text { Dye } C+0.557 * \text { Time } \\
& +0.0002 * \text { Salt } C\left(R^{2}=78.10\right)
\end{aligned}
$$

FTIR analysis was performed on the samples in the influent and effluent water with the highest removal efficiencies (COD and color) and the results are given in Fig. 7. As a result of the FTIR-ATR analysis, 2 peaks occurred mainly. No peaks occurred in the fingerprint region. Only the intensity of these peaks in the influent and effluent has changed. The detection of the peaks in the influent also in the effluent shows that these groups are persistent. The peaks occurred in the functional group region at the wavenumbers of $3000-3600 \mathrm{~cm}^{-1}\left(3323 \mathrm{~cm}^{-1}\right)$ and $1550-1700 \mathrm{~cm}^{-1}$ $\left(1662 \mathrm{~cm}^{-1}\right)$. These peaks may be attributed to $\mathrm{N}-\mathrm{H}$ stretching vibration in amines and amides or $\mathrm{O}-\mathrm{H}$ stretching vibration in phenols and may be attributed to $\mathrm{C}=\mathrm{C}$ stretching vibration in the alkene group or $\mathrm{C}=\mathrm{O}$ stretching vibration, respectively (Tezcan et al. 2019; Dincer et al. 2019).

Adsorption is commonly used even in different areas for removals of liquid or gas contaminants. The adsorption method is simple, easy to operate, toxic contaminants do not adversely affect the efficiency of the system and there is no excessive chemical consumption ( $\mathrm{pH}$ adjustment only) (Marungrueng and Pavasant 2006; GilPavas et al. 2019). Perhaps its biggest advantage is especially for colored wastewater. It provides color removal instead of causing the same or different color pollution compared to some methods (for example, Fenton). The reason for this is that chemicals that cause color formation are not added (Cakmak et al. 2017). Its most important disadvantage is the cost of the used adsorbent and the need to be disposed of after spending adsorbent.
This study was carried out to use the advantages of adsorption (decolorization, adsorbing chlorinated species, etc.) and because studies related to persulfate activation using activate carbon in the literature are very limited. PAC/PS oxidation system is also easy to operate. It is also a system that provides removals of harmful by-products that may result from toxic contaminants or their degradation. Acids-bases such as $\mathrm{NaOH}$ and/or $\mathrm{H}_{2} \mathrm{SO}_{4}$ for $\mathrm{pH}$ adjustment and persulfate are added. $\mathrm{pH}$ adjustment is carried out in all systems. Persulfate is not a harmful chemical.

There will be sulfate ions in the effluent water with the use of the PS especially when used more than optimum value. However, $\mathrm{S}_{2} \mathrm{O}_{8}{ }^{2-}$ is an inert substance and is not considered as a contaminant. It may only cause disruption of aesthetics. The United States Environmental Protection Agency (USEPA) has imposed an aesthetic limitation (maximum $250 \mathrm{mg} / \mathrm{L} ; 1.43 \mathrm{mM}$ ), especially for drinking water. PS is a much cheaper chemical compared to oxidants such as $\mathrm{H}_{2} \mathrm{O}_{2}$ and $\mathrm{O}_{3}$ (Salari et al. 2009). In this study, optimum values were determined for high color and COD removals in both the adsorption and HPS oxidation system catalyzed with PAC in order to compare the removal of acid yellow 17 from persistent and toxic azo dyes being a wide range of usage area.

Shortly, PAC/PS system is a hybrid system. In other words, it is a system where both adsorption and oxidation occur. It does not cause the color formation and sludge formation as in systems using an iron. The reusability of the adsorbent used is possible. In the studies conducted, the reusability of granular activate carbon was tested. In the third/fourth use, it was seen that low efficiencies were achieved (Yang et al. 2011). The most important parameters affecting the cost of the system are the dosage of adsorbent and persulfate. It is also a great advantage to use fewer adsorbents compared to the adsorption system.

For future studies, the effect of different anions may be studied, sulfate content may be determined in the effluent and the effect of sulfate on the environment may be discussed in more detail. Studies may be conducted on the removal of microorganisms, taking into account the disinfecting properties of potassium persulfate. The catalyst effect may be studied in the PS oxidation system by producing active adsorbents in order to reduce the cost of PAC. Dominant reactive species may be identified by adding different radical scavengers.

\section{Conclusion}

The removal of acid yellow 17 (AY17) dye was studied by using adsorption and heterogeneous persulfate oxidation systems together in different operating conditions to represent 
real textile wastewater. System performances were determined by color, COD, ORP, $\mathrm{pH}$ and FTIR analysis.

The adsorbent dosage, $\mathrm{pH}$ and reaction time from the operating parameters had a significant effect on both systems. Using PAC in the PS system (hybrid) increased mineralization compared to only adsorption or persulfate oxidation systems. The use of adsorbent in the hybrid system caused the reaction time to be shortened. It was concluded that acidic and neutral $\mathrm{pH}$ values are suitable for both adsorption and HPS (PAC/PS) system.

Shortly, toxic compounds such as textile dyestuffs may be successfully removed by adsorption and persulfate oxidation mechanisms with the use of chemicals (acids/bases for $\mathrm{pH}$ adjustment, persulfate) not resulting in additional pollution. Further, these methods are simple systems and easy to operate. This study will be a useful reference for future studies.

Acknowledgments I would like to thank Prof. Filiz Nuran Acar for allowing me to use laboratory facilities.

Author contributions Elanur Adar: Conceptualization, investigation, writing — original draft, review \& editing, supervision.

\section{Compliance with ethical standards}

Conflict of interest The author declares that there has no a known competing financial interest or personal relationships that could have appeared to influence the work reported in this paper. No funding was used in this study.

\section{References}

Ahmadi M, Behin J, Mahnam AR (2016) Kinetics and thermodynamics of peroxydisulfate oxidation of Reactive Yellow 84. J Saudi Chem Soc 20:644-650

APHA (2012) AWWA WEF, standard methods for the examination of water and wastewater. 22 edt., Washington, DC

Bayrak-Tezcan E, Ceylan Z, Acar FN (2019) Kinetics, isotherm and thermodynamic studies of the adsorption behavior of basic yellow 51 onto rice husk and burned rice husk. J Inst Sci Technol 9:1977-1988

Cakmak M, Tasar S, Selen V, Ozer D, Ozer A (2017) Removal of astrazon golden yellow 7GL from colored wastewater using chemically modified clay. J Cent South Univ 24:743-753

Chu W, Lau TK, Fung SC (2006) Effects of combined and sequential addition of dual oxidants $\left(\mathrm{H}_{2} \mathrm{O}_{2} / \mathrm{S}_{2} \mathrm{O}_{8}{ }^{2-}\right)$ on the aqueous carbofuran photodegradation. J Agric Food Chem 54:10047-10052

Deniz F, Sengul K (2015) Dye biosorption/desorption potential of Pinus brutia Ten. (Red pine) cone and leaf biomass. KSU J Eng Sci 17:19-25

Dincer A, Sevildik M, Aydemir T (2019) Optimization, isotherm and kinetics studies of azo dye adsorption on eggshell membrane. Int J Chem Technol 3:52-60

Erat N (2018) Optimization of removal of astrazon yellow 5GL Dye material from aqueous media by Fenton and $\mathrm{UV} / \mathrm{H}_{2} \mathrm{O}_{2}$ processes using Taguchi method. Master Thesis, Ataturk University, Turkey. https://tez.yok.gov.tr/UlusalTezMerkezi/
Eren Z, Acar FN, Ince NH (2010) Fenton and fenton-like oxidation of CI basic yellow 51: a comparative study. Color Technol 126:337-341

Ertugay N (2018) The removal of crystal violet (CV) dyestuff by wheat bran: kinetic studies. Erzincan Univ J Sci Technol 11:435-450

Frontistis Z, Hapeshi E, Fatta-Kassinos D, Mantzavinos D (2015) Ultraviolet-activated persulfate oxidation of methyl orange: a comparison between artificial neural networks and factorial design for process modelling. Photochem Photobiol Sci 14:528-535

Gao J, Zhang Q, Su K, Chen R, Peng Y (2010) Biosorption of acid yellow 17 from aqueous solution by non-living aerobic granular sludge. J Hazard Mater 174:215-225

GilPavas E, Dobrosz-Gomez I, Gomez-Garcia MA (2019) Optimization and toxicity assessment of a combined electrocoagulation, $\mathrm{H}_{2} \mathrm{O}_{2} / \mathrm{Fe}(2+) / \mathrm{UV}$ and activated carbon adsorption for textile wastewater treatment. Sci Total Environ 651:551-560

Gozmen B, Turabik M (2013) Response surface methodology for oxidative degradation of the Basic yellow 28 dye by temperature and ferrous ion activated persulfate. Asian J Chem 25:6831

Hori H, Yamamoto A, Hayakawa E, Taniyasu S, Yamashita N, Kutsuna S (2005) Efficient decomposition of environmentally persistent perfluorocarboxylic acids by use of persulfate as a photochemical oxidant. Environ Sci Technol 39:2383-2388

Imecik Z, Digrak M, Halipci HN (2014) Removal of Saffron from aqueous solution by using Platanus orienatlis L. biomass. Firat Univ J of Sci 26:139-145

Jedynak K, Wideł D, Rędzia N (2019) Removal of rhodamine b (a basic dye) and acid yellow 17 (an acidic dye) from aqueous solutions by ordered mesoporous carbon and commercial activated carbon. Colloids Interfaces 3:30

Khamparia S, Jaspal D (2016) Adsorptive removal of direct red 81 dye from aqueous solution onto Argemone mexicana. Sustain Environ Res 26:117-123

Khan NA, Khan SU, Ahmed S, Farooqi IH, Yousefi M, Mohammadi AA, Changani F (2020) Recent trends in disposal and treatment technologies of emerging-pollutants-A critical review. TrAC, Trends Anal Chem 122:115744

Khan NA, Ahmed S, Farooqi IH, Ali I, Vambol V, Changani F, Yousefi M, Vambol S, Khan SU, Khan AH (2020) Occurrence, sources and conventional treatment techniques for various antibiotics present in hospital wastewaters: a critical review. TrAC, Trends Anal Chem 129:115921

Koklu R, Ozer C (2018) Removal of Remazol Brilliant Blue R (RBBR) dyes with a low cost adsorbent, cigarette ash. Sakarya Univ J Sci 22:174-180

Kordkandi SA, Forouzesh M (2014) Application of full factorial design for methylene blue dye removal using heat-activated persulfate oxidation. J Taiwan Inst Chem Eng 45:2597-2604

Li D, Chen D, Yao Y, Lin J, Gong F, Wang L, Zhang L (2016) Strong enhancement of dye removal through addition of sulfite to persulfate activated by a supported ferric citrate catalyst. Chem Engineering J 288:806-812

Li J, Lin H, Zhu K, Zhang H (2017) Degradation of acid orange 7 using peroxymonosulfate catalyzed by granulated activated carbon and enhanced by electrolysis. Chemosphere 188:139-147

Liang CJ, Wang ZS, Mohanty N (2006) Influences of carbonate and chloride ions on persulfate oxidation of trichloroethylene at $20^{\circ} \mathrm{C}$. Sci Total Environ 370:271-277

Liu N, Ding F, Weng CH, Hwang CC, Lin YT (2018) Effective degradation of primary color direct azo dyes using $\mathrm{Fe} 0$ aggregatesactivated persulfate process. J Environ Manag 206:565-576

Marungrueng K, Pavasant P (2006) Removal of basic dye (Astrazon Blue FGRL) using macroalga Caulerpa lentillifera. J Environ Manag 78:268-274

Matzek LW, Carter KE (2016) Activated persulfate for organic chemical degradation: a review. Chemosphere 151:178-188 
Oyekanmi AA, Ahmad A, Hossain K, Rafatullah M (2019) Statistical optimization for adsorption of Rhodamine $\mathrm{B}$ dye from aqueous solutions. J Mol Liq 281:48-58

Peng J, Wu E, Wang N, Quan X, Sun M, Hu Q (2019) Removal of sulfonamide antibiotics from water by adsorption and persulfate oxidation process. J Mol Liq 274:632-638

Peng G, Li T, Ai B, Yang S, Fu J, He Q, Yu G, Deng S (2019) Highly efficient removal of enrofloxacin by magnetic montmorillonite via adsorption and persulfate oxidation. Chem Eng J 360:1119-1127

Pervez M, He W, Zarra T, Naddeo V, Zhao Y (2020) New sustainable approach for the production of $\mathrm{Fe}_{3} \mathrm{O}_{4} /$ graphene oxide-activated persulfate system for dye removal in real wastewater. Water $12: 733$

Pimol P, Khanidtha M, Prasert P (2008) Influence of particle size and salinity on adsorption of basic dyes by agricultural waste: dried seagrape (Caulerpa lentillifera). J Environ Sci 20:760-768

Salari D, Niaei A, Aber S, Rasoulifard MH (2009) The photooxidative destruction of CI basic yellow 2 using $\mathrm{UV} / \mathrm{S}_{2} \mathrm{O}_{8}{ }^{2-}$ process in a rectangular continuous photoreactor. J Hazard Mater 166:61-66

Salleh MAM, Mahmoud DK, Karim WAWA, Idris A (2011) Cationic and anionic dye adsorption by agricultural solid wastes: a comprehensive review. Desalination 280:1-13

Saputra E, Muhammad S, Sun H, Wang S (2013) Activated carbons as green and effective catalysts for generation of reactive radicals in degradation of aqueous phenol. RSC Adv 3:21905-21910

Serencam H, Ucurum M (2019) Performance evaluation of adsorption properties for $\mathrm{Ni}(\mathrm{II})$ removal with flying ash using Taguchi experimental design. Omer Halisdemir Univ J Eng Sci 8:336-344

Sharifi S, Nabizadeh R, Akbarpour B, Azari A, Ghaffari HR, Nazmara S, Mahmoudi B, Shiri L, Yousefi M (2019) Modeling and optimizing parameters affecting hexavalent chromium adsorption from aqueous solutions using Ti-XAD7 nanocomposite: RSMCCD approach, kinetic, and isotherm studies. J Environ Health Sci Eng 17(2):873-888

Teli MD, Nadathur GT (2018) Adsorptive removal of acid yellow 17 (an anionic dye) from water by novel ionene chloride modified electrospun silica nanofibres. J Environ Chem Eng 6:7257-7272
Tony MA, Parker HL, Clark JH (2019) Evaluating Algibon adsorbent and adsorption kinetics for launderette water treatment: towards sustainable water management. Water Environ J 33:401-408

Wacławek S, Lutze HV, Grübel K, Padil VV, Černík M, Dionysiou DD (2017) Chemistry of persulfates in water and wastewater treatment: a review. Chem Eng J 330:44-62

Wang J, Wang S (2018) Activation of persulfate (PS) and peroxymonosulfate (PMS) and application for the degradation of emerging contaminants. Chem Eng J 334:1502-1517

Weng $\mathrm{CH}$, Tao H (2018) Highly efficient persulfate oxidation process activated with $\mathrm{Fe} 0$ aggregate for decolorization of reactive azo dye remazol golden yellow. Arab J of Chem 11:1292-1300

Wu H, Wang S (2012) Impacts of operating parameters on oxidationreduction potential and pretreatment efficacy in the pretreatment of printing and dyeing wastewater by fenton process. J Hazard Mater 243:86-94

Wu J, Zhang H, Qiu J (2012) Degradation of Acid Orange 7 in aqueous solution by a novel electro/ $\mathrm{Fe}^{2+} /$ peroxydisulfate process. J Hazard Mater 215:138-145

Yang S, Wang P, Yang X, Shan L, Zhang W, Shao X, Niu R (2010) Degradation efficiencies of azo dye acid orange 7 by the interaction of heat, UV and anions with common oxidants: persulfate, peroxymonosulfate and hydrogen peroxide. J Hazard Mater 179:552-558

Yang S, Yang X, Shao X, Niu R, Wang L (2011) Activated carbon catalyzed persulfate oxidation of azo dye acid orange 7 at ambient temperature. J Hazard Mater 186:659-666

Yuan R, Ramjaun SN, Wang Z, Liu J (2011) Effects of chloride ion on degradation of acid orange 7 by sulfate radical-based advanced oxidation process: implications for formation of chlorinated aromatic compounds. J Hazard Mater 196:173-179

Zhang J, Shao X, Shi C, Yang S (2013) Decolorization of acid orange 7 with peroxymonosulfate oxidation catalyzed by granular activated carbon. Chem Eng J 232:259-265

Zıba CA, Akarsu S, Arslantas M, Dolaz M (2016) Tekstil atık sularında renk gidermede kullanılan koagulantlar: nişasta ve CMPS'nin floklaşmaya etkisi. KSU J Eng Sci 19:110-114 